\title{
Bias-dependent photo-detection of dual-ion beam sputtered MgZnO thin films
}

\author{
SAURABH KUMAR PANDEY* and SHAIBAL MUKHERJEE \\ Discipline of Electrical Engineering, Indian Institute of Technology, Indore 452003, India
}

MS received 23 July 2015; accepted 21 September 2015

\begin{abstract}
The structural, morphological, elemental and electrical properties of MgZnO thin films, grown on p-Si (001) substrates by dual-ion beam sputtering deposition (DIBSD) system at different substrate temperatures were thoroughly investigated. X-ray diffraction (XRD) pattern of MgZnO film exhibited crystalline hexagonal wurtzite structure with the preferred (002) crystal orientation. The full-width at half-maximum of the (002) plane was the narrowest with a value of $0.226^{\circ}$ from $\mathrm{MgZnO}$ film grown at $400^{\circ} \mathrm{C}$. X-ray photoelectron spectroscopy analysis confirmed the substitution of $\mathrm{Zn}^{2+}$ by $\mathrm{Mg}^{2+}$ in $\mathrm{MgZnO}$ thin films and the absence of $\mathrm{MgO}$ phase. Correlation between calculated crystallite size, as evaluated from XRD measurements, and room-temperature carrier mobility, as obtained from Hall measurements, was established. Current-voltage characteristics of MgZnO thin films were carried out under the influence of dark and light illumination conditions and corresponding values of photosensitivity were calculated. $\mathrm{MgZnO}$ film grown at $100^{\circ} \mathrm{C}$ exhibited the highest photosensitivity of 1.62. Compared with one of the best-reported values of photosensitivity factor from $\mathrm{ZnO}$-material-based films available in the literature, briefly, $\sim 3.085$-fold improved photosensitivity factor at the same bias voltage $(2 \mathrm{~V})$ was obtained.
\end{abstract}

Keywords. DIBSD; growth temperature; Hall measurements; MgZnO thin films; XRD; XPS.

\section{Introduction}

Ultraviolet (UV) photodectection have become subject of intense research because of various new requirements in technological fields, such as flame detection, engine monitoring, missile plume detection, chemical sensing and intersatellite communications [1,2]. ZnO-based material systems have been promising for advanced electronic and optoelectronic devices because of the availability of wide direct band gap of $3.37 \mathrm{eV}$ and large free exciton binding energy of $60 \mathrm{meV} \mathrm{[3-9]}$ at room temperature. $\mathrm{MgZnO}$ is an important semiconductor alloy for application to deep-UV photodetectors (PDs) and optoelectronic devices such as solar UV radiation monitors, ultrahigh temperature flame detectors, air-borne missile warning systems, space communication systems and ozone layer monitors [10,11]. Alloying $\mathrm{ZnO}$ films with $\mathrm{MgO}$ facilitates suitable band-gap engineering for device design. It has been reported that band gap energy increases considerably from 3.37 to $7.8 \mathrm{eV}$ on varying the $x$ composition for ternary compound $\mathrm{Mg}_{x} \mathrm{Zn}_{1-x} \mathrm{O}$ from 0 to 1 [11,12]. The ionic radius of $\mathrm{Mg}^{2+}(0.57 \AA)$ is similar to that of $\mathrm{Zn}^{2+}(0.6 \AA)$, so replacement of $\mathrm{Zn}^{2+}$ by $\mathrm{Mg}^{2+}$ should not cause a significant change in lattice constants [13]. In order to improve internal quantum efficiency of light emitters, the application of $\mathrm{MgZnO}$ layers as electron and hole blocking layers is quite essential [14].

\footnotetext{
*Author for correspondence (saurabh.rjit@gmail.com)
}

A number of deposition techniques have been deployed to grow $\mathrm{MgZnO}$ films such as pulsed-laser deposition [15], molecular beam epitaxy [16], metal-organic chemical vapour deposition [17,18] and radio frequency (RF) sputtering [19]. Among these deposition techniques, dual-ion beam sputtering deposition (DIBSD) technique is quite popular since it gives rise to high-quality and uniform film growth on larger substrate area at relatively lower substrate temperature $[20,21]$. Detailed descriptive analysis on the influence of growth temperature on the photoconducting properties of DIBSD-grown $\mathrm{MgZnO}$ has not been reported yet. Therefore, it will be extremely interesting to study the dependence of photoconduction of such $\mathrm{MgZnO}$ films in view of realizing high-performance optoelectronic and photovoltaic devices.

In this study, the effect of substrate temperature on the growth of ternary $\mathrm{MgZnO}$ films by DIBSD system has been discussed and characterizations of such films were performed to determine and correlate structural, elemental, morphological and electrical properties of thin $\mathrm{MgZnO}$ films. Currentvoltage $(I-V)$ characteristics of the $\mathrm{MgZnO}$ thin films were carried out in dark and under UV-illumination under different bias conditions.

\section{Experimental}

DIBSD system [22,23] was used to deposit MgZnO thin films of thickness $\sim 600 \mathrm{~nm}$ in the base pressure of $3 \times 10^{-4} \mathrm{mbar}$ on $\mathrm{p}-\mathrm{Si}$ (001) substrates. During the growth process, a 
secondary direct-current assist ion source with the primary $\mathrm{RF}$ ion source was deployed to increase the film adhesion to the substrate and to eventually realize more uniform film surface. Before inserting into DIBSD growth chamber, Si substrates were rinsed thoroughly with trichloro-ethylene, acetone, iso-propanol and de-ionized (DI) water and then purged by high-purity (99.999\%) $\mathrm{N}_{2}$ gas. Film growth was accomplished by sputtering a water-cooled, 4-in-diameter $\mathrm{Mg}_{0.1} \mathrm{Zn}_{0.9} \mathrm{O}$ target $(99.99 \%)$ at various substrate temperatures, ranging from 100 to $600^{\circ} \mathrm{C}$. During the reactive sputtering process, the flow rate ratio of oxygen $(99.999 \%)$ and argon gases $(99.999 \%)$ was maintained at $4: 2$ where primary ion beam power was kept constant at $65 \mathrm{~W}$.

The structural properties of $\mathrm{MgZnO}$ films were examined by X-ray diffraction (XRD) using a Bruker D8 Advance $\mathrm{X}$-ray diffractometer with a $\mathrm{Cu}-\mathrm{K}_{\alpha}$ radiation $(\lambda=0.154 \mathrm{~nm})$. $\mathrm{X}$-rays, produced inside a sealed tube, were detected after getting diffracted from the sample surface using a fast counting detector based on the silicon strip technology (Bruker Lynx Eye detector). Surface morphology and roughness of
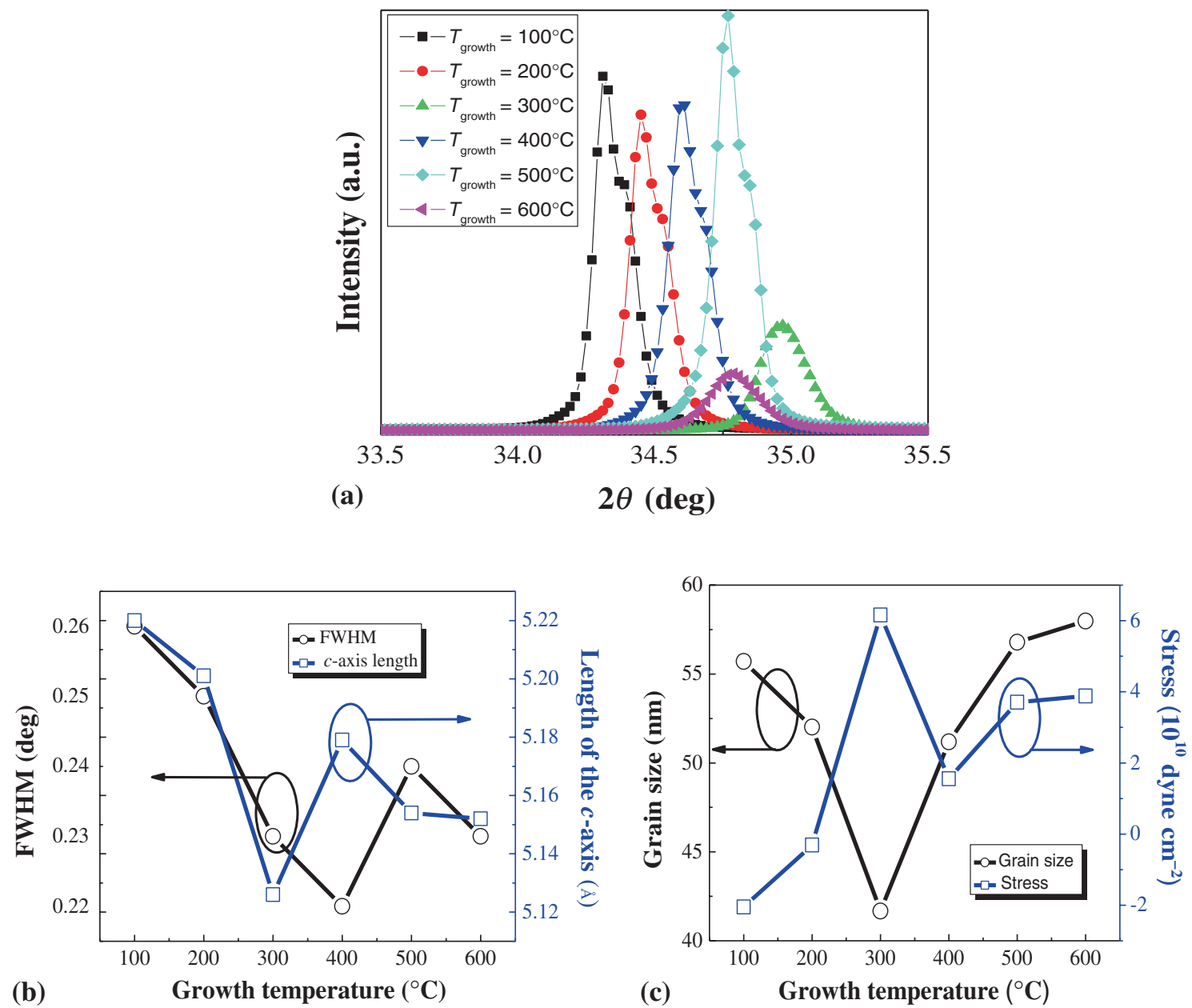

Figure 1. (a) XRD patterns of $\mathrm{MgZnO}(002)$ peaks, (b) FWHM and the $c$-axis length of MgZnO (002) peaks and (c) crystallite size and stress generation on $\mathrm{MgZnO}$ thin films for different growth temperatures.

Table 1. Influence of growth temperature on stress and crystallite size of $\mathrm{MgZnO}$ thin films grown on p-Si (001) substrate.

\begin{tabular}{|c|c|c|c|c|c|}
\hline $\begin{array}{l}\text { Growth temp. } \\
\left({ }^{\circ} \mathrm{C}\right)\end{array}$ & $\begin{array}{l}\text { (002) peak } \\
\text { value }\end{array}$ & $\begin{array}{l}\text { FWHM } \\
\text { (deg) }\end{array}$ & $\begin{array}{l}\text { Lattice constant, } \\
\qquad c(\AA)\end{array}$ & $\begin{array}{l}\text { Crystallite size } \\
\qquad(\mathrm{nm})\end{array}$ & $\begin{array}{c}\text { Stress }\left(\times 10^{10}\right. \\
\left.\text { dyne } \mathrm{cm}^{-2}\right)\end{array}$ \\
\hline 100 & 34.313 & 0.149 & 5.220 & 55.707 & -2.049 \\
\hline 200 & 34.450 & 0.160 & 5.201 & 52.011 & -0.306 \\
\hline 300 & 34.968 & 0.200 & 5.126 & 41.669 & +6.159 \\
\hline 400 & 34.597 & 0.163 & 5.179 & 51.180 & +1.554 \\
\hline 500 & 34.769 & 0.147 & 5.154 & 56.790 & +3.707 \\
\hline 600 & 34.786 & 0.144 & 5.152 & 57.977 & +3.879 \\
\hline
\end{tabular}


deposited films were measured by using advance integrated scanning tools for nano-technology (AIST-NT), atomic force microscope (AFM) and ZEISS Supra55 field-emission scanning electron microscope (FE-SEM). $I-V$ characteristics of the $\mathrm{MgZnO}$ thin films were measured by using $325 \mathrm{~nm}$ $\mathrm{He}-\mathrm{Cd}(10 \mathrm{~mW})$ laser and Keithley 2612A source meter.

$\mathrm{X}$-ray photoelectron spectroscopy (XPS) measurement was performed on $\mathrm{MgZnO}$ film grown at $300^{\circ} \mathrm{C}$ to validate the presence of elemental $\mathrm{Mg}$ in $\mathrm{MgZnO}$ using a PHOIBOS 100 analyzer with an $\mathrm{Al}-\mathrm{K}_{\alpha}$ radiation $(1486.6 \mathrm{eV})$ as an excitation source. The sample surface was pre-etched using $1 \mathrm{keV}$ Ar ion beam before performing XPS measurement to remove air contaminated top layer. Various chemical species were identified from their corresponding binding energies. The binding energies were determined by fitting the XPS spectral line shapes with Lorentzian-Gaussian functions. The room-temperature sheet-resistivity, carrier concentration and mobility of $\mathrm{MgZnO}$ thin films were measured by four-probe Hall-effect measurements in the van der Pauw configuration using 2612A Keithley source meter and a magnetic field of $\sim 0.5 \mathrm{~T}$.

\section{Results and discussion}

Figure 1a depicts the XRD pattern of $\mathrm{MgZnO}$ thin films grown on the p-Si (001) substrate as a function of substrate temperature. The $[\omega-2 \theta]$ XRD pattern clearly reveals that $\mathrm{MgZnO}$ thin films grown is highly $c$-axis oriented hexagonal wurtzite structures with preferred (002) crystal orientation as reported in existing literatures. It was observed from table 1 that the position of the (002) diffraction peak shifted from $34.313^{\circ}$ at $100^{\circ} \mathrm{C}$ to $34.968^{\circ}$ at $300^{\circ} \mathrm{C}$ and then became irregular and finally reached to $34.786^{\circ}$ for the film deposited at $600^{\circ} \mathrm{C}$. It is well known that the angular peak position of $\mathrm{Mg}_{0.1} \mathrm{Zn}_{0.9} \mathrm{O}$ powder is located at $34.473^{\circ}$ [24].

The shift in the corresponding diffraction peak position for different growth temperatures was mainly due to strain produced within the films during growth process. The angular peak position of film grown at $100^{\circ} \mathrm{C}$, as observed in figure $1 \mathrm{a}$, is less than the angular value of $\mathrm{Mg}_{0.1} \mathrm{Zn}_{0.9} \mathrm{O}$ powder peak; indicating that the lattice constant $(c)$ of the $\mathrm{MgZnO}$ films was elongated as compared with the $\mathrm{MgZnO}$ single crystal and the unit cells are under compressive stress. It was also observed that with an increase in growth temperature, the $c$-axis plane peak position shifted towards the angular value of $\mathrm{Mg}_{0.1} \mathrm{Zn}_{0.9} \mathrm{O}$ powder peak. The peak position becomes $34.450^{\circ}$ at a substrate temperature of $200^{\circ} \mathrm{C}$. However, for even higher growth temperatures such as 300, 400, 500 and $600^{\circ} \mathrm{C}$, the $(002)$ peak positions were again observed to deviate from the angular value of powder peak but in the opposite direction, indicating change in the direction of stress as compared with unstressed $\mathrm{MgZnO}$ films [24].
The lattice constant for $\mathrm{MgZnO}$ films was evaluated from Vegard's law [25] and was used to calculate stress on $\mathrm{MgZnO}$ films grown on Si substrates [26].

$$
\begin{aligned}
& c=5.2042-0.072 x, \\
& a=3.2491+0.047 x, \\
& \sigma=-4.5 \times 10^{12}\left(\frac{c-c_{0}}{c_{0}}\right) .
\end{aligned}
$$

The crystallite size $(D)$ was calculated from the well-known Scherrer's formula [27]:

$$
D=\frac{0.9 \lambda}{A \cos \theta},
$$

where $\lambda$ is the X-ray wavelength, $A$ the full-width at halfmaximum (FWHM) of the (002) diffraction peak and $\theta$ the Bragg diffraction angle of the (002) peak.

Numerical results demonstrated that $\mathrm{MgZnO}$ crystallite size was minimum with a value $41.6 \mathrm{~nm}$ at $300^{\circ} \mathrm{C}$ growth

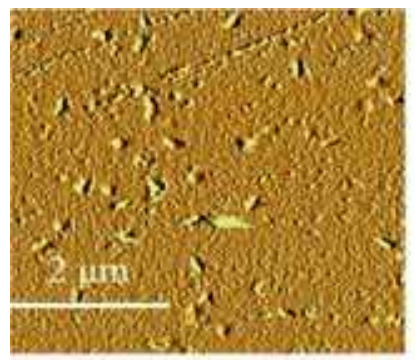

(a)

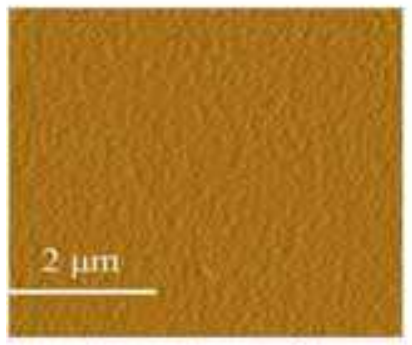

(c)

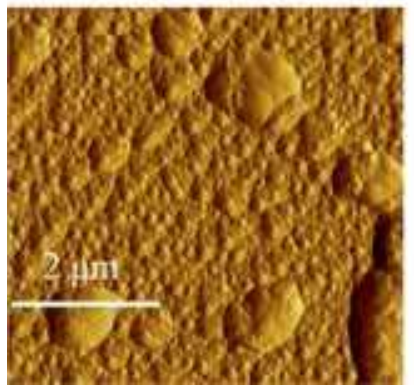

(e)

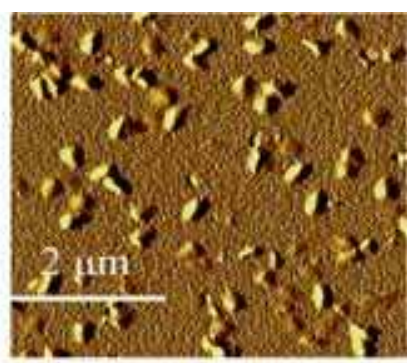

(b)

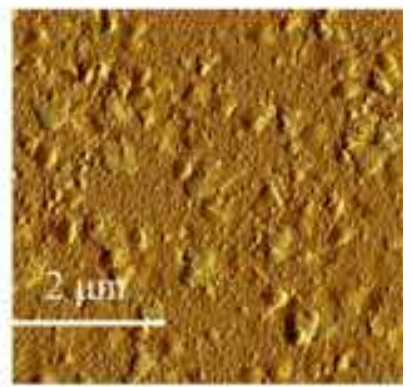

(d)

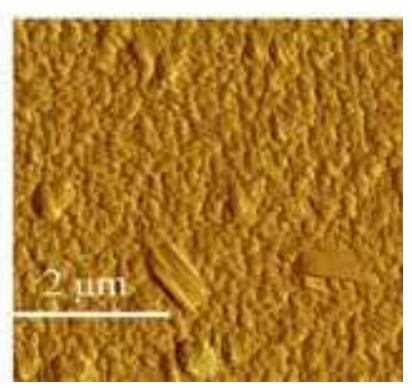

(f)
Figure 2. AFM images $(5 \mu \mathrm{m} \times 5 \mu \mathrm{m}$ scale $)$ of $\mathrm{MgZnO}$ films deposited at the growth temperatures: (a) $100^{\circ} \mathrm{C}$ (b) $200^{\circ} \mathrm{C}$ (c) $300^{\circ} \mathrm{C}$ (d) $400^{\circ} \mathrm{C}$ (e) $500^{\circ} \mathrm{C}$ and (f) $600^{\circ} \mathrm{C}$. 
temperature and maximum with a value of $57.9 \mathrm{~nm}$ at $600^{\circ} \mathrm{C}$ growth temperature. Stress on films increased from $-2.0486 \times 10^{10}$ to $3.879 \times 10^{10}$ dyne $\mathrm{cm}^{-2}$ as growth temperature increased from 100 to $600^{\circ} \mathrm{C}$. The minimum stress value of $-0.30641 \times 10^{10}$ dyne $\mathrm{cm}^{-2}$ was achieved for $\mathrm{MgZnO}$ film grown at $200^{\circ} \mathrm{C}$.

Table 1 shows the influence of growth temperature on stress and crystallite size of $\mathrm{MgZnO}$ thin films grown on the p-Si (001) substrate.

Atomic force microscopy (AFM) images shown in figure $2 \mathrm{a}-\mathrm{f}$ illustrate the effect of growth temperature on surface morphology of $\mathrm{MgZnO}$ thin films. A maximum surface roughness of $70 \AA$ on a $5 \mu \mathrm{m} \times 5 \mu \mathrm{m}$ scale, was observed for the $\mathrm{MgZnO}$ film grown at $600^{\circ} \mathrm{C}$. $\mathrm{MgZnO}$ film grown at $300^{\circ} \mathrm{C}$ was found to have minimum surface roughness of $17.5 \AA$.

Figure 3 describes the surface FE-SEM micrographs of the $\mathrm{MgZnO}$ films on $\mathrm{Si}$ substrates at temperature range 200, 400 and $600^{\circ} \mathrm{C}$. $\mathrm{MgZnO}$ films were found to exhibit columnar, dense and hexagonal crystallites. The crystallite size and the morphology of film grown at $600^{\circ} \mathrm{C}$ showed larger and smooth surface.

The chemical states of zinc and magnesium elements was analysed by XPS. All XPS spectra were calibrated by the C 1s peak $(284.6 \mathrm{eV})$ to compensate the charge effect. The addition of $\mathrm{Mg}$ to $\mathrm{ZnO}$ can either replace $\mathrm{Zn}^{2+}$ or form $\mathrm{MgO}$ secondary phase [28]. In the case of pure $\mathrm{ZnO}$, the $\mathrm{Zn} 2 \mathrm{p}_{3 / 2}$ XPS peak appeared at $1022.03 \mathrm{eV}$ represents the formation of $\mathrm{Zn}-\mathrm{O}$ bonds while in case of $\mathrm{MgZnO}$ films, the $\mathrm{Zn} 2 \mathrm{p}_{3 / 2}$ peak shifted towards higher binding energies, which results from the replacement of $\mathrm{Zn}^{2+}$ by $\mathrm{Mg}^{2+}$ and an added $\mathrm{Zn}-\mathrm{O}-\mathrm{Mg}$ binding energy. Figure 4a shows XPS spectra of the $\mathrm{O}$ 1s core level in $\mathrm{MgZnO}$ films. The curve had been deconvoluted to generate three distinct and nearly Gaussian curves centred at binding energy levels of $529.6 \mathrm{eV}$ (blue), $531 \mathrm{eV}$ (green) and $531.8 \mathrm{eV}$ (red). The oxygen (O 1s) spectra described the presence of both oxygen vacancies and interstitials in the film grown at $300^{\circ} \mathrm{C}$. Oxygen interstitial defect concentration was found to be higher than vacancies since the intensity of $531.8 \mathrm{eV}$ binding energy peak was larger than that at $529.6 \mathrm{eV}$.

Figure $4 \mathrm{~b}$ shows the core level spectra of $\mathrm{Mg} 2 \mathrm{p}_{3 / 2}$ in $\mathrm{MgZnO}$ thin film. The $\mathrm{Mg} \mathrm{2} \mathrm{p}_{3 / 2}$ XPS peak in the $\mathrm{MgZnO}$ thin film centred at around $49.6 \mathrm{eV}$ can be ascribed to the presence of $\mathrm{Mg}^{2+}$ replacing $\mathrm{Zn}^{2+}$ [29]. No positive $\mathrm{Mg} 2 \mathrm{p}_{3 / 2}$ binding energy shift towards the $\mathrm{Mg} \mathrm{2} \mathrm{p}_{3 / 2}$ $(\mathrm{MgO})$ binding energy of around $50-51 \mathrm{eV}$ was identified, which was in correlation with the absence of $\mathrm{MgO}$ phase.

Figure 4c illustrates the XPS spectra of $\mathrm{Zn} 2 \mathrm{p}$ levels in $\mathrm{MgZnO}$ thin films. The peaks of $\mathrm{Zn} 2 \mathrm{p}_{3 / 2}$ and $\mathrm{Zn} 2 \mathrm{p}_{1 / 2}$ spectra were appeared at binding energy values of 1022.03 and $1045.07 \mathrm{eV}$, respectively. This indicates the presence of the stable $\mathrm{Zn}-\mathrm{O}$ bonds in $\mathrm{ZnO}$ crystal lattice structure. The binding energy difference between $\mathrm{Zn} 2 \mathrm{p}_{3 / 2}$ and $\mathrm{Zn} 2 \mathrm{p}_{1 / 2}$ was calculated to be $23.04 \mathrm{eV}$, which was characteristic value of $\mathrm{ZnO}$ [30-32].
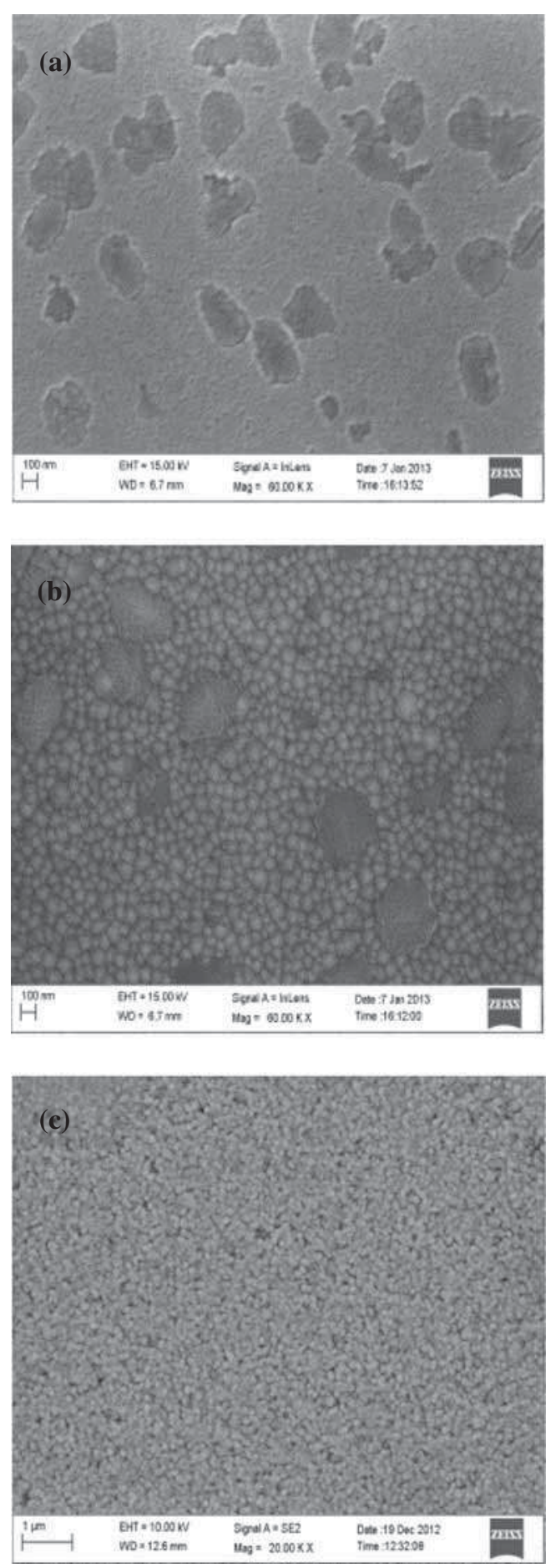

Figure 3. FE-SEM images of $\mathrm{MgZnO}$ samples grown on $\mathrm{p}-\mathrm{Si}$ substrates at (a) $200^{\circ} \mathrm{C}$ (b) $400^{\circ} \mathrm{C}$ and (c) $600^{\circ} \mathrm{C}$.

The variation of electrical properties of $\mathrm{MgZnO}$ films deposited at various substrate temperatures had been illustrated in figure 5. $\mathrm{MgZnO}$ films grown within the temperature range of $100-600^{\circ} \mathrm{C}$ showed $n$-type conductivity with high electron concentration of $10^{18} \mathrm{~cm}^{-3}$, owing to the existence of native donor defects, such as $\mathrm{O}$ vacancies. $\mathrm{MgZnO}$ film, grown at $100^{\circ} \mathrm{C}$, was found to have the highest carrier mobility of $40.25 \mathrm{~cm}^{2} \mathrm{~V}^{-1} \mathrm{~s}^{-1}$ at room temperature with resistivity of 
(a)

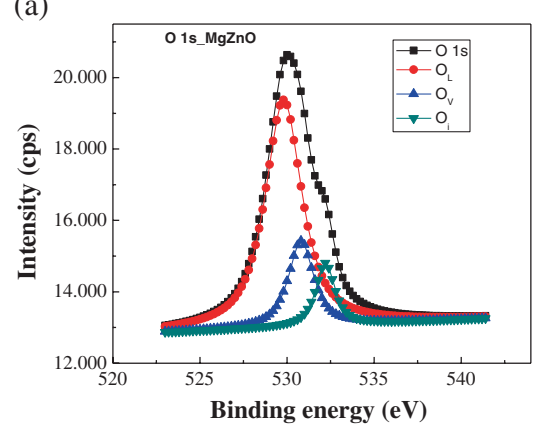

(b)

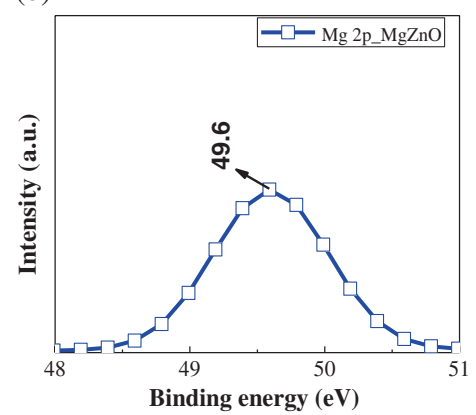

(c)

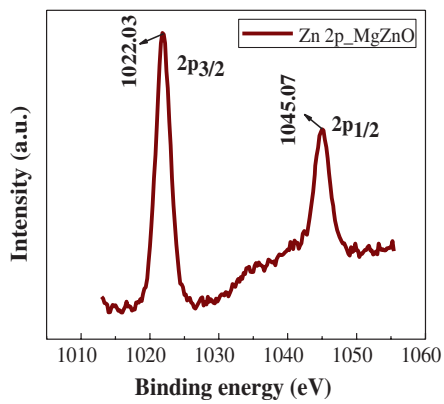

Figure 4. XPS spectra of (a) $\mathrm{O} 1 \mathrm{~s}\left(\mathrm{O}_{\mathrm{i}}, \mathrm{O}_{\mathrm{L}}\right.$ and $\mathrm{O}_{\mathrm{v}}$ represented oxygen interstitials, lattice point and vacancies, respectively); (b) $\mathrm{Mg} 2 \mathrm{p}$ peak at $49.6 \mathrm{eV}$; and (c) $\mathrm{Zn} 2 \mathrm{p}$ having two sharp peaks at 1022.03 and $1045.07 \mathrm{eV}$ in as-deposited $\mathrm{MgZnO}$ thin film grown at $300^{\circ} \mathrm{C}$ substrate temperature with $\mathrm{Ar} / \mathrm{O}_{2}$ ratio $2: 4$ at $\mathrm{RF}$ power $=65 \mathrm{~W}$.

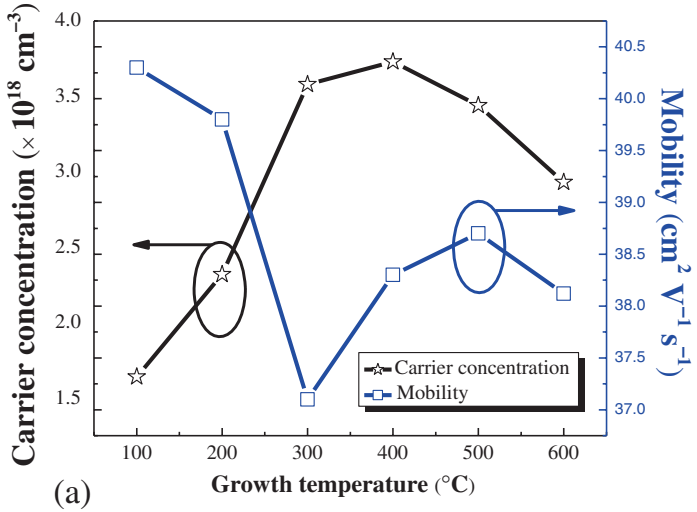

(a)

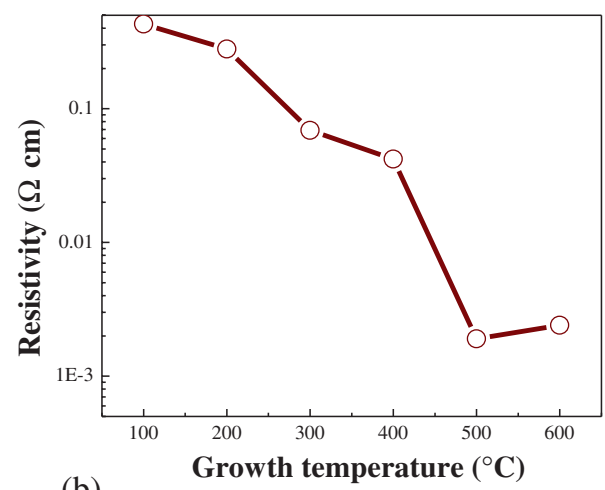

(b)

Figure 5. Variation of (a) carrier concentration and mobility and (b) resistivity of $\mathrm{MgZnO}$ thin films on Si at different substrate temperatures.

$4.29 \times 10^{-1} \Omega \mathrm{cm}$ and electron concentration of $1.53 \times 10^{18}$ $\mathrm{cm}^{-3}$. The free carrier mobility was almost 1.5 times higher than that obtained from $\mathrm{MgZnO}$ film grown by the other solid-state deposition techniques elsewhere [33,34]. It was observed that the structural properties of as-grown $\mathrm{MgZnO}$ thin films had a strong correlation with electrical properties. Calculated crystallite sizes of $\mathrm{MgZnO}$ grown at different substrate temperatures, as obtained from XRD measurements were observed to follow the same trend as carrier mobility values formulated by Hall measurement. At $300^{\circ} \mathrm{C}$ growth temperature, both carrier mobility and crystallite size were found to be minimum with values around $37 \mathrm{~cm}^{2} \mathrm{~V}^{-1} \mathrm{~s}^{-1}$ and $41.67 \mathrm{~nm}$, respectively. The possible explanation could be as when the crystallite size is small, the probability of having carriers to face more number of grain boundaries to move across the same distance along $\mathrm{MgZnO}$ surface and this might result in the reduction of carrier mobility.

$I-V$ characteristics, as illustrated in figure 6 , of $\mathrm{MgZnO}$ thin films under dark and under the influence of light illumination conditions were measured at room temperature, which is shown in figure 6. A non-linear behaviour in the semi-logarithmic $I-V$ curves was observed in the MgZnO thin films in both dark and under light illumination. In case of light illumination, as there was an increase of the generation of electron-hole pairs in $\mathrm{MgZnO}$ films, non-ohmic behaviour was observed $[35,36]$. Due to the generation of more chargecarrying carriers, the value of current at a given bias voltage is larger in case of light illumination as compared with the corresponding value in dark conditions [35,36].

The photosensitivity of a semiconductor can be expressed as [37].

$$
S=\frac{I_{\text {light }}-I_{\mathrm{dark}}}{I_{\mathrm{dark}}} .
$$

The photosensitivity characteristics of the $\mathrm{MgZnO}$ films under different bias conditions are described in figure 7 . $\mathrm{MgZnO}$ film grown at $100^{\circ} \mathrm{C}$ exhibited the highest photosensitivity of 1.62 , when excited by the incident light. As observed from figure 7, the photosensitivity factor initially reduced somewhat as $\mathrm{MgZnO}$ growth temperature was increased up to $300^{\circ} \mathrm{C}$, and then it improved marginally. This 


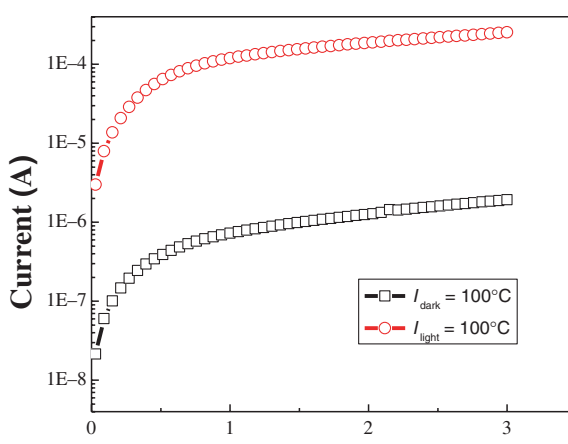

(a)

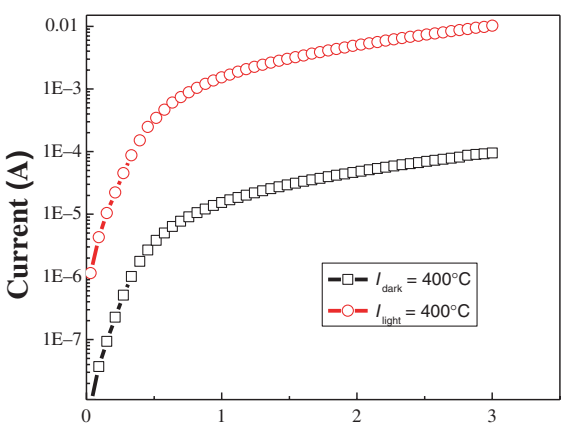

(d)

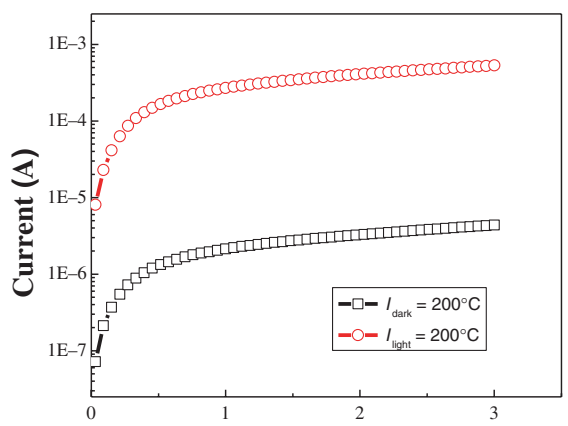

(b)

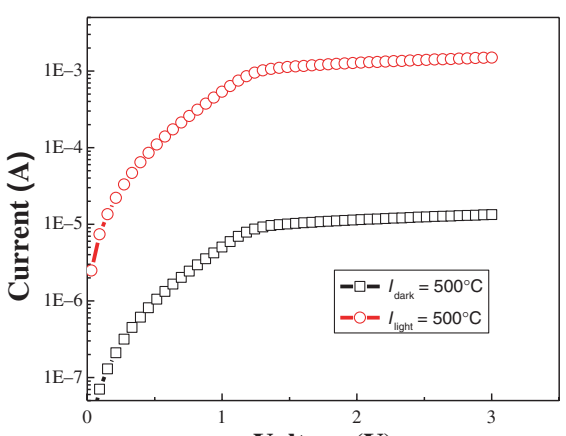

(e)

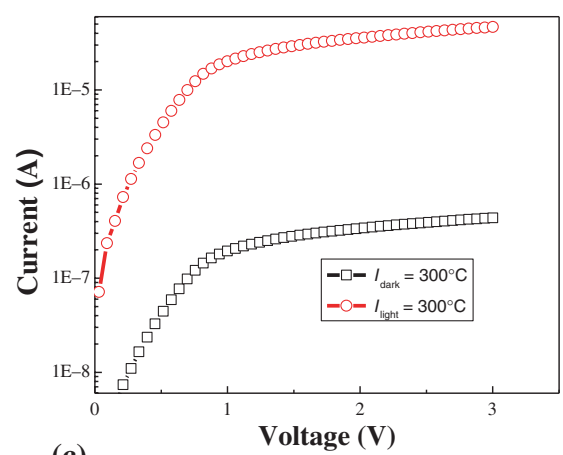

(c)

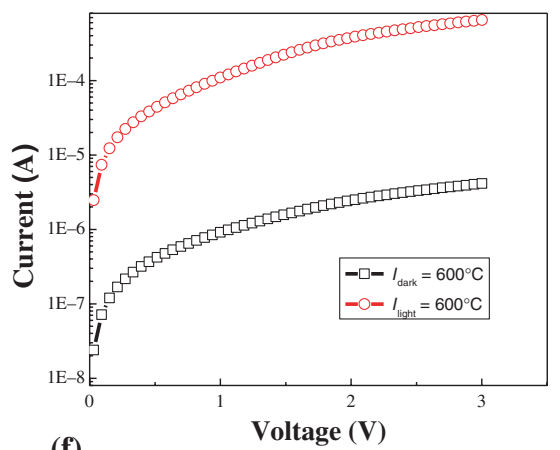

(f)

Figure 6. Semi-logarithmic $(I-V)$ characteristics of $\mathrm{MgZnO}$ thin films (a) under dark condition and (b) under light illumination at temperatures: (a) 100, (b) 200, (c) 300, (d) 400, (e) 500 and (f) $600^{\circ} \mathrm{C}$.

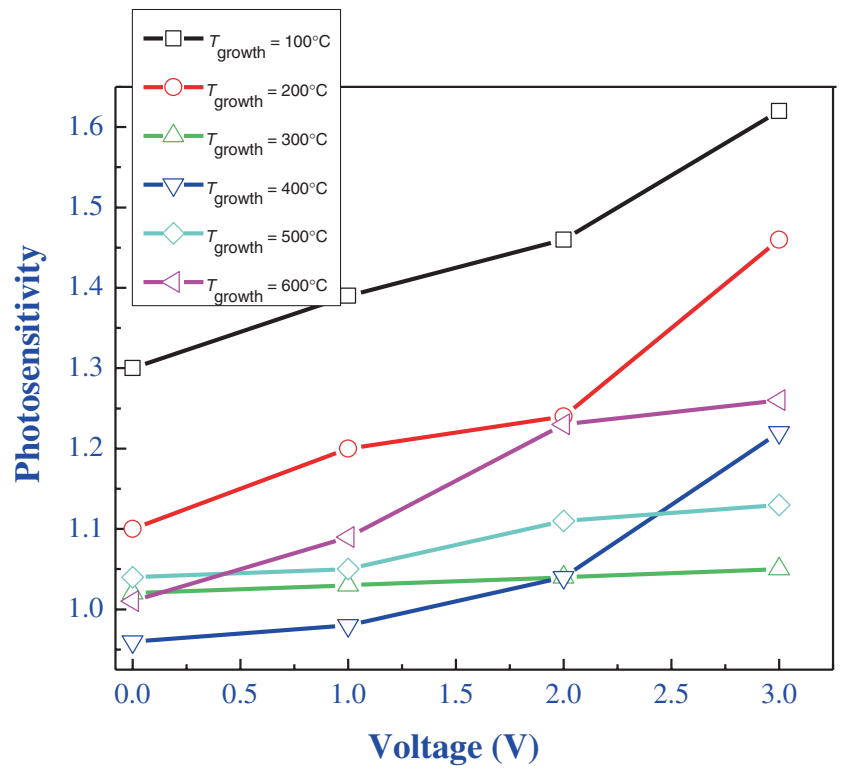

Figure 7. Photosensitivity factor w.r.t. voltage of $\mathrm{MgZnO}$ films.

behaviour was replicated by the carrier mobility variation with film growth temperature, as described in figure 5a. Compared with one of the best-reported values of photosensitivity factor from $\mathrm{ZnO}$-material-based films available in the literature [38], 3.085-fold improved photosensitivity factor at the same bias voltage $(2 \mathrm{~V})$ was obtained. This actually confirmed superior growth quality of $\mathrm{MgZnO}$ films by DIBSD system. From the figure, it could be inferred that the grown $\mathrm{MgZnO}$ films are perfectly suitable for high-performance UV-detector and photosensor applications.

\section{Conclusion}

In summary, wurtzite $\mathrm{Mg}_{0.1} \mathrm{Zn}_{0.9} \mathrm{O}$ thin films were deposited on the Si (001) substrate using DIBSD system and systematically studied to analyse the effect of growth temperature on structural, electrical and morphological properties of films. Smooth, high quality and preferred $c$-axis oriented $\mathrm{MgZnO}$ films can be synthesized by using $\mathrm{Mg}_{0.1} \mathrm{Zn}_{0.9} \mathrm{O}$ target at $\mathrm{RF}$ power of $65 \mathrm{~W}$ with $\mathrm{Ar} / \mathrm{O}_{2}$ gas flow ratio of $2: 4$. The minimum stress value of $-0.31 \times 10^{10}$ dyne $\mathrm{cm}^{-2}$ was achieved for $\mathrm{MgZnO}$ film grown at $200^{\circ} \mathrm{C}$. XPS studies confirmed the substitution of $\mathrm{Zn}^{2+}$ by $\mathrm{Mg}^{2+}$ in $\mathrm{MgZnO}$ thin films and the absence of $\mathrm{MgO}$ phase. At $300^{\circ} \mathrm{C}$, both carrier mobility and crystallite size were found to be minimum with values around $37 \mathrm{~cm}^{2} \mathrm{~V}^{-1} \mathrm{~s}^{-1}$ and $41.67 \mathrm{~nm}$, respectively. $\mathrm{MgZnO}$ film, grown at $100^{\circ} \mathrm{C}$, was observed to have the highest carrier mobility of $40.25 \mathrm{~cm}^{2} \mathrm{~V}^{-1} \mathrm{~s}^{-1}$ at room temperature with a resistivity value of $4.29 \times 10^{-1} \Omega \mathrm{cm}$ and electron concentration of $1.53 \times 10^{18} \mathrm{~cm}^{-3}$. Correlation between calculated crystallite size, as evaluated from XRD measurements and room-temperature carrier mobility, obtained from Hall measurements, was established for $\mathrm{MgZnO}$, grown at different growth temperatures. A non-linear behaviour in the semi-logarithmic $I-V$ curves was observed in the $\mathrm{MgZnO}$ 
thin films in both dark and under light illumination. $\mathrm{MgZnO}$ film grown at $100^{\circ} \mathrm{C}$ exhibited the highest photosensitivity of 1.62, when excited by the incident light. Compared with one of the best-reported values of photosensitivity factor from ZnO-material-based films, 3.085-fold improved photosensitivity factor at the same bias voltage $(2 \mathrm{~V})$ was obtained. From the measurement results, it could be inferred that the DIBSD-grown MgZnO films are perfectly suitable for highperformance UV-detector and photovoltaic applications.

\section{Acknowledgements}

This work was partially supported by Department of Science and Technology (DST) Fast Track Scheme for Young Scientist No. SR/FTP/ETA-101/2010. This work was also supported by DST Science and Engineering Research Board (SERB) project number SR/S3/EECE/0142/2011 and Council of Scientific and Industrial Research (CSIR) project number 22(0608)/12/EMR-II. We are also grateful for the Atomic Force Microscopy (AFM) Facility equipped at Sophisticated Instrument Centre (SIC), IIT Indore. We also express gratitude to Dr Mukul Gupta, UGC-DAE CSR, Indore, for XRD measurement of samples.

\section{References}

[1] Liao M and Koide Y 2006 Appl. Phys. Lett. 89113509

[2] Moon T H, Jeong M C, Lee W and Myoung J M 2005 Appl. Surf. Sci. 240280

[3] Look D C 2001 Mater. Sci. Eng. B 80383

[4] Polyakov A Y, Smirnov N B, Kozhukhova E A, Vdovin V I, Ip K, Heo Y W, Norton D P and Pearton S J 2003 Appl. Phys. Lett. 831575

[5] Theodoropoulou N A, Hebard A F, Norton D P, Budai J D, Boatner L A, Lee J S, Khim Z G, Park Y D, Overberg M E, Pearton S J and Wilson R G 2003 Solid-State Electron. 47 2231

[6] Kim H S, Pearton S J, Norton D P and Ren F 2008 Appl. Phys. A 912

[7] Heo Y W, Tien L C, Norton D P, Kang B S, Ren F, Gila B P and Pearton S J 2004 Appl. Phys. Lett. 852002

[8] Kwon Y, Li Y, Heo Y W, Jones M, Holloway P H, Norton D P, Park Z V and Li S 2004 Appl. Phys. Lett. 842685

[9] Tuzemen S, Gur E, Yildirım T, Xiong G and Williams R T 2006 J. Appl. Phys. 100103513

[10] Studenikin S A, Golego N and Cocivera M 2000 J. Appl. Phys. 872413

[11] Sharma P, Mansingh A and Sreenivas K 2002 Appl. Phys. Lett. 80553

[12] Yang W, Hullavarad S S, Nagaraj B, Takeuchi I, Sharma R P, Venkatesan T, Vispute R D and Shen H 2003 Appl. Phys. Lett. 823424
[13] Ohtomo A, Kawasaki M, Koida T, Masubuchi K and Koinuma H 1998 Appl. Phys. Lett. 722466

[14] Pandey S K, Pandey S K and Mukherjee S 2013 Proceeding of the 5th IEEE international nanoelectronics conference (INEC, Singapore)

[15] Liang M H, Ho Y T, Wang W L, Peng C Y and Li C 2008 J. Cryst. Growth $\mathbf{3 1 0} 1847$

[16] Lu Y M, Wu C X, Wei Z P, Zhang Z Z, Zhao D X and Zhang J Y 2005 J. Cryst. Growth 278299

[17] Park W I, Yi G and Jang H M 2001 Appl. Phys. Lett. 79 2022

[18] Liu W, Gu S L, Zhu S M, Ye J D, Qin F and Liu S M et al 2005 J. Appl. Phys. 277416

[19] Minemoto T, Negami T, Nishiwaki S, Takakura $H$ and Hamakawa Y 2000 Thin Solid Films 372173

[20] Choi C H and Kim S H 2005 J. Cryst. Growth 283 170

[21] Kar J P, Jeong M C, Lee W K and Myoung J M 2008 Mater. Sci. Eng. B 14774

[22] Pandey S K, Pandey S K, Mukherjee C, Mishra P, Gupta M, Barman S R, D'Souza S W and Mukherjee S 2013 J. Mater. Sci.: Mater. Electron. 242541

[23] Pandey S K, Pandey S K, Deshpande U P, Awasthi V, Kumar A, Gupta M and Mukherjee S 2013 Semicond. Sci. Technol. 28085014

[24] American Standard for Testing of Materials-ASTM 36-1451

[25] Asharfi A B and Segawa Y 2005 J. Vac. Sci. Technol. B 235

[26] Kumar R, Khare N, Kumar V and Bhalla G L 2008 Appl. Surf. Sci. 25420

[27] Cullity B D 1978 Elements of X-ray diffraction (Reading: Addison-Wesley) 2nd ed, p 102

[28] Park S M, Gu G H and Park C G 2011 Phys. Status Solidi A 2082688

[29] Lee C Y, Tseng T Y, Li S Y and Lin P 2006 J. Appl. Phys. 99 024303

[30] Rao Kumar M C S, Safarulla A, Ganesan V, Barman S R and Sanjeeviraja C 2010 Physica B $\mathbf{4 0 5} 2226$

[31] Islam M N, Ghosh T B, Chopra K L and Acharya H N 1996 Thin Solid Films 28020

[32] Fan H B, Yang S Y, Zhang P F, Wei H Y, Liu X L, Jiao C M, Zhu Q S, Chen Y H and Wang Z G 2007 Chinese Phys. Lett. 242108

[33] Kim H S, Lugo F, Pearton S J and Norton D P 2008 J. Vac. Sci. Technol. B 26960

[34] Liu C Y, Xu H Y, Wang L, Li X H and Liu Y C 2009 J. Appl. Phys. 106073518

[35] Ilican S, Caglar Y and Caglar M 2008 J. Optoelectron. Adv. Mater. 1010

[36] Caglar Y, Caglar M, Ilican S and Ates A 2009 J. Phys. D: Appl. Phys. 42065421

[37] George P J, Sanchez-Juarez A and Nair P K 1996 Semicond. Sci. Technol. 111090

[38] Zhou H, Fang G, Liu N and Zhao X 2011 Nanoscale Res. Lett. 6147 